\title{
Effectiveness of Beetroot Juice as Adjuvant Therapy on Blood Pressure among Patients with Hypertension
}

\author{
Soumya M. ${ }^{1, *}$, Snehaleeza V. L. ${ }^{2}$ \\ ${ }^{1}$ Lecturer, Department of Medical Surgical Nursing, College of Nursing, Sri Ramakrishna \\ Institute of Paramedical Sciences, Coimbatore, Tamil Nadu, India \\ ${ }^{2}$ Assisstant Professor, Department of Medical Surgical Nursing, Government College of \\ Nursing, Alappuzha, Kerala, India
}

\begin{abstract}
The present study was intended to assess the effectiveness of beetroot juice as adjuvant therapy on blood pressure among patients with hypertension attending Noncommunicable Disease Clinic, Ambalappuzha. Quasi experimental one group pre-test post-test design was adopted. A sample of 35 patients with hypertension was selected consecutively. The tool consisted of an interview schedule to determine the sociopersonal and clinical data and a standardized calibrated mercury sphygmomanometer and stethoscope to measure the blood pressure. 1 week apart, two pre-test blood pressure measurements were taken at patient's home. The researcher administered $200 \mathrm{ml}$ of beetroot juice to the patients before breakfast for 14 consecutive days in addition to existing antihypertensive drug therapy. Post-test blood pressure measurements were taken on the 8th and 15th day of initiating the therapy at patient's home. It was found that the pre-test value of systolic BP, $148.13 \pm 5.36 \mathrm{~mm} \mathrm{Hg}$ was reduced to $139.29 \pm 5.43 \mathrm{~mm} \mathrm{Hg}$ and the pre-test value of diastolic BP, $92.52 \pm 3.05 \mathrm{~mm} \mathrm{Hg}$ was reduced to $88.39 \pm 4.39 \mathrm{~mm} \mathrm{Hg}$ after adjuvant therapy for 14 consecutive days. Paired-t test revealed a crucial difference in the level of blood pressure among patients with hypertension after adjuvant therapy with beetroot juice $(p=<0.001)$. Chi-square analysis showed that there was no significant association between change in blood pressure and selected variables among patients with hypertension. The study concluded that beetroot juice as adjuvant therapy was effective in reducing blood pressure among patients with hypertension.
\end{abstract}

Keywords: adjuvant therapy, beetroot juice, blood pressure, hypertension, systolic

*Corresponding Author

E-mail: soumyasubramani2015@gmail.com

\section{INTRODUCTION}

Hypertension is a silent killer. It is a long-term medical condition in which blood pressure in the arteries is persistently elevated [1]. High blood pressure usually does not cause any symptoms [2]. Prolonged hypertension is a major risk factor for coronary artery disease, stroke, heart failure, peripheral vascular disease, loss of vision and chronic kidney disease [3].

The study conducted at Imperial College, London, revealed that the number of people in the world with raised blood pressure increased from 594 million in 1975 to 1.13 billion in 2015 , with the increase largely in low-income and 
middle-income countries [4]. Recent studies showed that with every person having hypertension there are two persons with either undiagnosed hypertension or pre-hypertension [5].

According to WHO Global status report on NCDs, every fourth individual in India aged above 18 years has raised blood pressure (hypertension) and the prevalence has increased by $10 \%$ from 2010 to 2014 [6]. Prevalence of hypertension is rapidly increasing among both urban and rural populations. In fact, hypertension is the most prevalent chronic disease in India [7]. The prevalence of hypertension ranges from 20 to $40 \%$ in urban adults and 12$17 \%$ among rural adults. The number of hypertensive patients is projected to increase from 118 million in 2000 to 2024 million in 2025 , with nearly equal number of men and women [8].

It is dangerous to ignore high blood pressure, because this increases the chances of life-threatening complications [9]. The estimated direct and indirect cost of high blood pressure for 2011-2012 (annual average) was $\$ 48.6$ billion. Thus, controlling hypertension in all patients with cardiovascular diseases and stage 2 hypertension could be effective and costsaving [10].

\section{NEED AND SIGNIFICANCE OF THE STUDY}

The World Health Statistics report showed that globally, cardiovascular disease accounts for approximately 17 million deaths a year, nearly one third of the total [11]. Of these, complications of hypertension account for 9.4 million deaths worldwide every year. Hypertension is responsible for at least $45 \%$ of deaths due to heart disease and $51 \%$ of deaths due to stroke [12].

Even a moderate reduction in systolic BP (SBP) of $10 \mathrm{~mm} \mathrm{Hg}$ or diastolic blood pressure (DBP) of $5 \mathrm{~mm} \mathrm{Hg}$ has been found to decrease average risk of mortality from coronary heart disease and stroke by 22 and $41 \%$, respectively [13]. Reducing blood pressure can decrease cardiovascular risk and this can be achieved by lifestyle measures in mild cases and it should be the commencing approach to manage hypertension in all cases. This mainly includes dietary modifications, weight reduction, exercise and smoking cessation. Dietary modifications include reducing salt, and increasing potassium and nitrate diet.

Nitrate, which is found in all vegetables and is particularly abundant in beetroot, has emerged as a possible mediating component for the cardiovascular health benefits associated with high vegetable consumption. Dietary nitrate is reduced to bioactive nitrite by facultative anaerobic bacteria in the saliva and further to nitric oxide via various pathways. Endotheliumderived nitric oxide is a potent vasodilator, governs systemic BP, retards atherogenesis and inhibits platelet aggregation [14].

To assess whether dietary nitrate might provide sustained BP lowering in patients with hypertension, a double-blind, placebo-controlled clinical trial was done among 68 patients with hypertension. Patients were randomly assigned to receive daily dietary supplementation for 4 weeks with either dietary nitrate $(250 \mathrm{ml}$ daily, as beetroot juice) or a placebo $(250 \mathrm{ml}$ daily, as nitrate-free beetroot juice). Daily supplementation with dietary nitrate was associated with reduction in blood pressure which was measured by three different methods. Mean reduction in clinic BP was $7.7 / 2.4 \mathrm{~mm} \mathrm{Hg}, 24 \mathrm{~h}$ ambulatory $\mathrm{BP}$ was reduced by $7.7 / 5.2 \mathrm{~mm} \mathrm{Hg}$ and home $\mathrm{BP}$ was reduced by $8.1 / 3.8 \mathrm{~mm} \mathrm{Hg}$ [15].

Investigator from her field of experience and through extensive literature realized that most of the hypertensive patients are 
not affordable for the high cost of antihypertensives that resulted in a nonadherence to the drugs. Thus, people ended up with complications of hypertension such as stroke, coronary artery disease, myocardial infarction, kidney failure, heart failure, hypertensive crisis (hypertensive urgency, hypertensive emergency, hypertensive encephalopathy) that affect their quality of life and decrease their longevity. Uncontrolled hypertension in patients those who are on single antihypertensive drug forces them to take multi-drug therapy of which all these drugs have many side effects like weakness, dizziness, fainting, headache and joint pain. The observed high incidence of complications even among those on treatment due to poor compliance and side effects explains the need to manage hypertension with a minimum cost and maximum effectiveness.

Hence, the investigator thought of doing a study to assess the effectiveness of beetroot juice as adjuvant therapy on blood pressure among patients with hypertension. Such interventions would assist the patients to manage hypertension appropriately. It would also assist the policy makers in developing context specific and relevant policies capable of improving the management of hypertension. Ultimately it is envisioned that the implementation of cost effective strategies would lead to increased levels of controlled blood pressure and reduced occurrence of complications.

\section{STATEMENT OF THE PROBLEM}

Effectiveness of beetroot juice as adjuvant therapy on blood pressure among patients with hypertension attending Noncommunicable Disease Clinic, Ambalappuzha.

\section{Objectives}

1. To find out the effectiveness of beetroot juice as adjuvant therapy on blood pressure among patients with hypertension.

2. To find out the association between change in blood pressure and selected variables among patients with hypertension.

\section{Operational Definitions \\ Effectiveness}

Effectiveness refers to the difference in blood pressure among patients with hypertension before and after adjuvant therapy with beetroot juice.

\section{Beetroot Juice}

Beetroot juice refers to $200 \mathrm{ml}$ of freshly prepared juice made of $50 \mathrm{~g}$ peeled slices of beetroot ground with $150 \mathrm{ml}$ of boiled cooled water and filtered.

\section{Adjuvant Therapy}

Adjuvant therapy refers to the therapy with beetroot juice, administered every morning before breakfast for 14 consecutive days in addition to the antihypertensive drug therapy.

\section{Patients with Hypertension}

Patients with hypertension refers to those individuals clinically diagnosed to have stage I hypertension for more than 6 months and on antihypertensive medication with systolic and diastolic blood pressure of $140-159$ or $90-99 \mathrm{~mm}$ $\mathrm{Hg}$ respectively, attending Noncommunicable Disease Clinic of Urban Health Training Centre (UHTC), Ambalappuzha.

\section{Stage I Hypertension}

Stage I hypertension refers to systolic blood pressure 140-159 mm $\mathrm{Hg}$ or diastolic blood pressure 90-99 $\mathrm{mm} \mathrm{Hg}$.

\section{Hypotheses}

- $\mathbf{H}_{1}$ : There is a significant difference in the level of blood pressure among patients with hypertension before and 
after adjuvant therapy with beetroot juice.

- $\mathbf{H}_{2}$ : There is a significant association between change in blood pressure and selected variables among patients with hypertension.

\section{METHODS AND MATERIALS}

- Research Approach: Quantitative research approach.

- Research Design: Quasi experimental one group pretest posttest design.

- Setting of the Study: Noncommunicable Disease Clinic of Urban Health Training Centre (UHTC), Ambalappuzha and the field area under UHTC, Ambalappuzha.

- Population: Patients with hypertension.

- Sample: Patients clinically diagnosed to have stage I hypertension, attending Noncommunicable Disease Clinic of Urban Health Training Centre (UHTC), Ambalappuzha.

- Sample Size: 35 patients with hypertension.

- Sampling Technique: Samples fulfilling the inclusion criteria were selected consecutively.

\section{Criteria for Sample Selection: \\ Inclusion Criteria}

Patients with stage I hypertension:

- in the age group of 35-65 years,

- duration of more than 6 months,

- on antihypertensive medication, and

- With systolic and diastolic blood pressure of $140-159$ or $90-99 \mathrm{~mm} \mathrm{Hg}$ respectively.

\section{Exclusion Criteria}

Patients with stage I hypertension:

- with diabetes mellitus,

- with secondary hypertension,

- with polycythaemia, and

- practicing any other complementary therapies.

\section{DESCRIPTION OF TOOL}

Tool 1: Interview Schedule to Assess the Socio-Personal and Clinical Data

- Section A: Include age, gender, education, occupation, monthly family income, marital status, type of family, supportive members, area of residence and unhealthy habits.

- Section B: Include body mass index, duration of hypertension, family history of hypertension, duration on antihypertensive medication treatment, regular intake of drugs, adherence to dietary modifications, performance of regular exercise, adequacy of sleep and presence of comorbidities.

\section{Tool 2: Standardised Calibrated Mercury Sphygmomanometer and Stethoscope to Assess Blood Pressure}

\section{DATA COLLECTION PROCESS}

After getting permission from Medical Officer of Urban Health Training Centre (UHTC), Ambalappuzha, 35 patients with hypertension attending Noncommunicable Disease Clinic of Urban Health Training Centre (UHTC), Ambalappuzha who fulfilled the criteria were selected consecutively. Established rapport explained the purpose of the study and then obtained informed consent from patients. Socio-personal and clinical data were collected using structured interview schedule of 10 min duration.

The blood pressure was assessed preferably in the upper arm using standardized calibrated mercury sphygmomanometer and stethoscope after a resting period of $5 \mathrm{~min}$. Two more blood pressure measurements were taken $1 \mathrm{~min}$ apart and the mean of these three measurements were recorded as the blood pressure of the patient. On the 8th day (pre-test 1) and on the 15th day (pre-test 2 ), the investigator measured and recorded the blood pressure by the same method in 
their home. The purpose of performing two pre-tests seven days apart by the investigator was to ensure the stability of the single group as the study did not have a control group.

On the 15th day of sample selection, patients or significant others were demonstrated to prepare $200 \mathrm{ml}$ of beetroot juice $(50 \mathrm{~g}$ peeled slices of fresh beetroot ground with $150 \mathrm{ml}$ of boiled cooled water and filtered) by the investigator. The needed quantity of fresh beetroot $(50 \mathrm{~g})$ to prepare beetroot juice were peeled and weighed using standardized calibrated weighing scale in front of the patients or significant others and it was provided for the patient by the investigator. Then, the patients were instructed to drink $200 \mathrm{ml}$ of beetroot juice before breakfast in the presence of investigator. The beetroot juice was prepared by the patients or significant others and patients were made to drink it in front of the investigator every morning between 6:15 AM and 9:00 AM before breakfast during the time of home visit for 14 consecutive days in addition to existing antihypertensive drug therapy.

Blood pressures of patients were again measured and recorded on the 8th and 15th day of initiating the therapy with beetroot juice by the investigator during the home visit. Patients were informed to continue their medications as ordered by the physician regularly and if they experience any discomforts, to report to the investigator or to their doctor in Urban Health Training Centre, Ambalappuzha.

Among the selected 35 samples, 4 patients were dropped out from the study for reasons as two of them were not present during the intervention and other two patients were not available during posttest.

\section{DATA ANALYSIS AND INTERPRETATION}

The data gathered were organized, tabulated and interpreted based on the objectives of the study using descriptive and inferential statistics.

\section{Section I: Frequency and Percentage Distribution of Socio-demographic Variables among Patients with Hypertension}

Table 1 shows that $60 \%$ of patients with hypertension belonged to the age group of 56-65 years and $14.3 \%$ of patients with hypertension belonged to the age group of 35-45 years.

Figure 1 shows that $42.9 \%$ of the patients with hypertension were males and $57.1 \%$ were females.

Table 1. Distribution of patients with hypertension based on age $(n=35)$.

\begin{tabular}{|l|c|c|}
\hline Age (years) & Frequency & Percentage (\%) \\
\hline $35-45$ & 5 & 14.3 \\
\hline $46-55$ & 9 & 25.7 \\
\hline $56-65$ & 21 & 60.0 \\
\hline
\end{tabular}

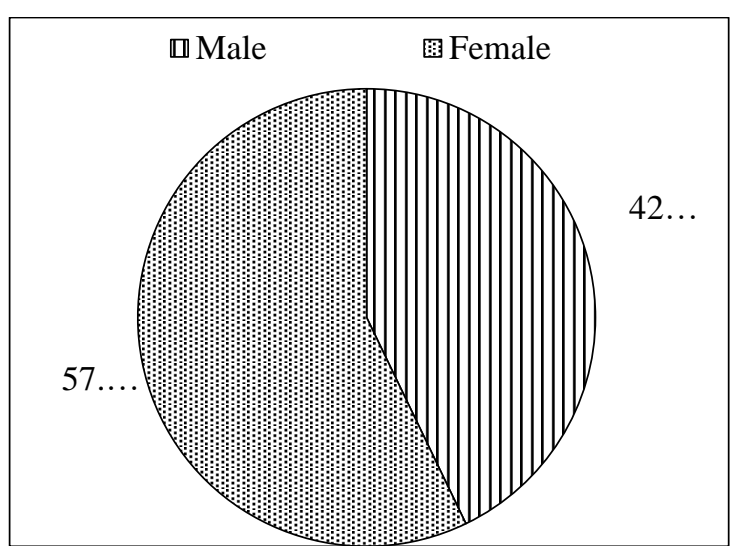

Fig. 1. Distribution of patients with hypertension based on gender $(n=35)$.

Table 2 shows that $60 \%$ had BMI within normal range (18.50-22.99), 5.7\% were underweight $(<18.5)$ and $11.4 \%$ were obese $(>27.50)$.

Among the selected 35 patients with hypertension, four patients were dropped 
out from the study for reasons as two of them were not present during the intervention and other two patients were not available during post-test. Thus, analyses of the following sections were done in the data collected from the remaining 31 samples.

Table 2. Distribution of patients with hypertension based on body mass index

$(n=35)$.
\begin{tabular}{|l|c|c|}
\hline \multicolumn{1}{|c|}{ Body Mass Index } & Frequency & Percentage $(\%)$ \\
\hline$<18.5$ (Underweight) & 2 & 5.7 \\
\hline $\begin{array}{l}18.50-22.99 \quad \text { (Normal } \\
\text { range) }\end{array}$ & 21 & 60.0 \\
\hline $23-27.49$ (Overweight) & 8 & 22.9 \\
\hline$>27.50$ (Obese) & 4 & 11.4 \\
\hline
\end{tabular}

\section{Section II: Comparison of Blood} Pressures of Pre-Test 1 and Pre-Test 2 before Adjuvant Therapy with Beetroot Juice

Table 3 shows that the ' $t$ ' values obtained on statistical analysis were 2.03 and 1.43 , which was not significant at 0.05 level. This denotes that there was no statistically significant difference in pre-interventional blood pressure values (pre-test 1 and pretest 2) among patients with hypertension. The blood pressure values were remaining stable that ensures the stability of the one group.

\section{Section III: Effectiveness of Beetroot Juice as Adjuvant Therapy on Blood Pressure among Patients with \\ Hypertension \\ Effectiveness of Beetroot Juice as Adjuvant Therapy on Systolic Blood Pressure among Patients with Hypertension}

Table 4 shows $\pm 5.12 \mathrm{~mm} \mathrm{Hg}$ on 8th day of initiation of beetroot juice as adjuvant therapy and $139.29 \pm 5.43 \mathrm{~mm} \mathrm{Hg}$ after adjuvant therapy with beetroot juice for 14 consecutive days. The difference between the pre-test and post-test values was found to be statistically significant at 0.001 level. Thus, null hypothesis was not accepted and it can be interpreted that beetroot juice as adjuvant therapy is effective in reducing systolic blood pressure among patients with hypertension.

Table 3. Mean, standard deviation and ' $t$ ' value of two pre-test blood pressures before adjuvant therapy with beetroot juice among patients with hypertension $(n=31)$.

\begin{tabular}{|l|l|l|c|c|c|}
\hline $\begin{array}{l}\text { S. } \\
\text { No. }\end{array}$ & BP & Observation & $\begin{array}{l}\text { Mean } \\
(\mathbf{m m} \text { Hg) }\end{array}$ & $\begin{array}{l}\text { Standard } \\
\text { Deviation }\end{array}$ & $\begin{array}{l}\text { 't' } \\
\text { Value }\end{array}$ \\
\hline 1 & $\begin{array}{l}\text { Systolic } \\
\text { BP }\end{array}$ & Pre-test 1 & 148.58 & 5.61 & \multirow{2}{*}{2.03} \\
\cline { 2 - 5 } & Pre-test 2 & 148.13 & 5.36 & \\
\hline 2 & $\begin{array}{l}\text { Diastolic } \\
\text { BP }\end{array}$ & Pre-test 1 & 92.65 & 2.96 & \multirow{2}{*}{1.43} \\
\cline { 3 - 5 } & Pre-test 2 & 92.52 & 3.05 & \\
\hline
\end{tabular}

Table 4. Mean, standard deviation and ' $t$ ' value of pre-test and post-test systolic blood pressure before and after adjuvant therapy with beetroot juice among patients with hypertension $(n=31)$.

\begin{tabular}{|l|l|c|c|c|}
\hline $\begin{array}{c}\text { S. } \\
\text { No. }\end{array}$ & Observation & $\begin{array}{c}\text { Mean } \\
(\mathbf{m m ~ H g})\end{array}$ & $\begin{array}{c}\text { Standard } \\
\text { Deviation }\end{array}$ & ' $\mathbf{t}$ ' Value \\
\hline 1 & Pre-Test 2 & 148.13 & 5.36 & \multirow{2}{*}{$17.34 * * *$} \\
\hline 2 & Post-Test 1 & 142.39 & 5.12 & \\
\hline 3 & Pre-Test 2 & 148.13 & 5.36 & \multirow{2}{*}{$21.43 * * *$} \\
\hline 4 & Post-Test 2 & 139.29 & 5.43 & \\
\hline \multicolumn{5}{|c}{$* * *$ Significant at 0.001 level. } \\
\hline
\end{tabular}

\section{Effectiveness of Beetroot Juice as} Adjuvant Therapy on Diastolic Blood Pressure among Patients with

\section{Hypertension}

Table 5 shows $\pm 4.07 \mathrm{~mm} \mathrm{Hg}$ on 8 th day of initiation of beetroot juice as adjuvant therapy and $88.39 \pm 4.39 \mathrm{~mm} \mathrm{Hg}$ after adjuvant therapy with beetroot juice for 14 consecutive days. The difference between the pre-test and post-test values was found to be statistically significant at 0.001 level. Thus, null hypothesis was not accepted and it can be interpreted that beetroot juice as adjuvant therapy is effective in reducing diastolic blood pressure among patients with hypertension.

Hence, it is concluded that beetroot juice as adjuvant therapy is effective in reducing blood pressure among patients with hypertension. 
Table 5. Mean, standard deviation and ' $t$ ' value of pre-test and post-test diastolic blood pressure before and after adjuvant therapy with beetroot juice among patients with hypertension $(n=31)$.

\begin{tabular}{|c|c|c|c|c|}
\hline \begin{tabular}{|c|} 
S. \\
No.
\end{tabular} & Observation & $\begin{array}{c}\text { Mean } \\
(\mathrm{mm} \mathrm{Hg})\end{array}$ & $\begin{array}{l}\text { Standard } \\
\text { Deviation }\end{array}$ & $\begin{array}{c}\text { 't' } \\
\text { Value }\end{array}$ \\
\hline 1 & Pre-test 2 & 92.52 & 3.05 & \\
\hline 2 & Post-test 1 & 89.42 & 4.07 & $8.97 * * *$ \\
\hline 3 & Pre-test 2 & 92.52 & 3.05 & \\
\hline 4 & Post-test 2 & 88.39 & 4.39 & $8.27 * * *$ \\
\hline
\end{tabular}

\section{Section IV: Association between Change in Blood Pressure and Selected Variables among Patients with Hypertension}

Chi-square analysis indicated that there was no statistically significant association between change in blood pressure and selected variables among patients with hypertension.

\section{RESULTS AND DISCUSSION}

The present study investigated the effectiveness of beetroot juice as adjuvant therapy on blood pressure among patients with hypertension and found that the systolic blood pressure was reduced by $8.84 \pm 0.14 \mathrm{~mm} \mathrm{Hg}$ and diastolic blood pressure was reduced by $4.13 \pm 0.49 \mathrm{~mm}$ $\mathrm{Hg}$ after adjuvant therapy with $200 \mathrm{ml}$ of beetroot juice for 14 consecutive days. A double-blind, placebo-controlled clinical trial conducted at Queen Mary University of London, to assess whether dietary nitrate provide sustained blood pressure lowering in patients with hypertension among 68 participants strongly supports this finding by illustrating that daily supplementation with $250 \mathrm{ml}$ of beetroot juice for 4 weeks reduced systolic blood pressure and diastolic blood pressure by 8.1/3.8 mm Hg [16].

The present study results showed that beetroot juice as adjuvant therapy significantly reduced the systolic blood pressure after 2 weeks of intervention $(8.84 \pm 0.14 \mathrm{~mm} \mathrm{Hg})$. This was supported by the findings of a study done at Newcastle upon Tyne in the North-East of England which showed that beetroot juice concentrate reduced daily systolic blood pressure after 3 weeks $(7.3 \pm 5.9 \mathrm{~mm} \mathrm{Hg})$. However, the effect was not maintained after the interruption of the supplementation (week 4, 2.8 $\pm 6.1 \mathrm{~mm} \mathrm{Hg}$, $\mathrm{p}=0.09$ ) [17].

The findings of the present study highlight that there was a significant reduction in blood pressure after consumption of $200 \mathrm{ml}$ of beetroot juice $(50 \mathrm{~g}$ peeled slices of fresh beetroot ground with $150 \mathrm{ml}$ of boiled cooled water and filtered) for a period of 14 days and there was no statistically significant association between change in blood pressure and selected variables. This finding was consistent with a similar community based quasi experimental study conducted in Nellore, Andhra Pradesh, India which revealed that there was a significant reduction in blood pressure after consumption of $400 \mathrm{ml}$ of beetroot juice $(50 \mathrm{~g}$ beetroot mixed with $350 \mathrm{ml}$ water) for a period of 7 days and there was no statistically significant association between post-test blood pressure scores with their selected sociodemographic variables [18].

\section{LIMITATIONS}

- The study was limited to a particular geographical area (Noncommunicable Disease Clinic of Urban Health Training Centre (UHTC), Ambalappuzha.) which imposes limits on generalization.

- Small size was very small to generalize the findings.

- Samples were selected consecutively.

- The study used one group pre-test and post-test design, considered as a weak design to establish causal relationship between independent and dependent. Thus, using control group could have given more strength to the study 
findings and made the design more strong.

- Immediate effect of the intervention could not be assessed in the present study.

\section{RECOMMENDATIONS}

- A separate Nurse-run hypertension clinic in the outpatient department can be started to identify hypertensive patients and to provide health education and counselling services for patients and families.

- A special nursing unit for implementing and analysing the use of adjuvant therapy in the management of various disease conditions including beetroot juice for hypertension can be organized in each institution.

- Long term efficacy of beetroot juice needs to be tested in people at higher cardiovascular risk, together with an assessment of the tolerance, safety, compliance and cost effectiveness of the intervention.

- A follow up study can be conducted to find out whether the positive effects of the intervention are persisting or not.

\section{CONCLUSION}

In the present study, it was found that the beetroot juice as adjuvant therapy was effective in reducing blood pressure among patients with hypertension. It is simple, cost effective and can be added to the management protocol for hypertensive patients in addition to the existing treatments.

\section{REFERENCES}

[1] Naish J, Court DS. Medical Sciences. 2nd Edn. London: Elsevier Publishers; 2014.

[2] Whelton PK, Carey RM, Aronow WS, Casey DE, Collins KJ, Dennison C, et al. 2017 ACC/AHA/AAPA/ ABC/ACPM/AGS/APhA/ASH/ASP C/NMA/PCNA Guideline for the
Prevention, Detection, Evaluation, and Management of High Blood Pressure in Adults External Icon. Hypertension. 2018; 71(19): e13-115p.

[3] Lackland DT, Weber MA. Global Burden of Cardiovascular Disease and Stroke: Hypertension at the Core. The Canadian Journal of Cardiology. 2015; 31(5): 569-571p.

[4] Wighton K, Bentham J, et al. Worldwide Trends in Blood Pressure from 1975 to 2015: A Pooled Analysis of 1479 Population-Based Measurement Studies with 19.1 million Participants. Lancet. 2017; 389(10064): 37-55p.

[5] Joshi SR, Saboo BS, et al. Prevalence of Diagnosed and Undiagnosed Diabetes and Hypertension in India: Results from Screening India's Twin Epidemic (SITE) Study. Diabetes Technol Ther. 2012; 14(1): 8-15p.

[6] World Health Organization. Burden of NCDs and Their Risk Factors in India (Excerpted from Global Status Report on NCDs -2014. Mar 2017. [Online] Available from http://www. searo.who.int/india/topics/noncommu nicable_diseases/ncd_situation_globa 1_report_ncds_2014.pdf?ua=1

[7] Guptha R, Gupta S. Strategies for Initial Management of Hypertension. Indian J Med Res. 2010; 132(5): 531-542p.

[8] Reddy KS. Regional Case Studies, India. Nestle Nutr Workshop Ser Pediatr Program. 2009; 63(1): 259-268p.

[9] Heidenreich PA, Trogdon JG, et al. Forecasting the Future of Cardiovascular Disease in the United States: A Policy Statement from the American Heart Association. Circulation. 2011; 123(1): 933-944p.

[10] Moran AE, Odden MC, et al. CostEffectiveness of Hypertension Therapy according to 2014 Guidelines. $N$ Engl J Med. 2015; 372(2): 447-455p. 
[11] World Health Organization. Global Status Report on Non-communicable Diseases. 2014. [Online] Available from https://www.who.int/nmh/publi cations/ncd-status-report-2014/en/

[12] Lim SS, Vos T, et al. A Comparative Risk Assessment of Burden of Disease and Injury Attributable to Risk Factors and Risk Factor Clusters in 21 Regions, 1990-2010: A Systematic Analysis for the Global Burden of Disease Study 2010. Lancet. 2012; 380(9859): 2224-2260p.

[13] Law MR, Morris JK, et al. Use of Blood Pressure Lowering Drugs in the Prevention of Cardiovascular Disease: Meta-Analysis of 147 Randomised Trials in the Context of Expectations from Prospective Epidemiological Studies. BMJ. 2009; 338: b1665p.

[14] Gupta R, Gupta S. Strategies for initial management of hypertension. Indian J Med Res [Internet]. 2010 Nov [cited 2016 Dec 16]; 132(5):[about 12 p.]. Available from: http://www.ijmr.org.in/text.asp?2010/ 132/5/531/73388

[15] Kapil V, Khambata RS, Robertson A, Caulfield MJ, Ahluwalia, et al. Dietary Nitrate Provides Sustained Blood Pressure Lowering in Hypertensive Patients: A Randomized, Phase 2, Double-Blind, Placebo-Controlled Study. Hypertension. 2015; 65(2): 320-327p.

[16] Siervo M, Lara J, et al. Inorganic Nitrate and Beetroot Juice Supplementation Reduces Blood Pressure in Adults: A Systematic Review and Meta-Analysis. J Nutri. 2013; 143(6): 818-826p.

[17] Indira S, Kalpana B. Effectiveness of Beetroot Juice on Blood Pressure among Patients with Hypertension. IJRSR. 2015; 6(6): 4880-4840p.

[18] Indira S, Kalpana B. Effectiveness of Beetroot Juice on Blood Pressure among Patients with Hypertension. IJRSR. 2015; 6(6):4880-4840p.

Cite this Article: Soumya M., Snehaleeza V. L. Effectiveness of Beetroot Juice as Adjuvant Therapy on Blood Pressure among Patients with Hypertension. International Journal of Cardiovascular Nursing. 2020; 6(2): 1-9p. 